\title{
A Picture of the Research Field of Doctoral Education from the pÿStudents Perspectives : Studies Using Questionnaires and Scales
}

\section{Cerrato Lara, Maria}

Palgrave Macmillan

2019

Cerrato Lara , M , Castelló, M \& Lonka , K 2019 , A Picture of the Research Field of pÿDoctoral Education from the Students Perspectives : Studies Using Questionnaires and Scales . in T M Machin , M Clarà \& P A Danaher (eds), Traversing the Doctorate : Reflections and strategies from students, supervisors and administrators . Palgrave Studies in Education Research Methods, Palgrave Macmillan, Cham , pp. 75-89 . https://doi.org/10.1007/978-3-030-23731

http://hdl.handle.net/10138/334579

https://doi.org/10.1007/978-3-030-23731-8_5

unspecified

acceptedVersion

Downloaded from Helda, University of Helsinki institutional repository.

This is an electronic reprint of the original article.

This reprint may differ from the original in pagination and typographic detail.

Please cite the original version. 


\title{
A picture of the research field of doctoral education from the students' perspectives: studies using questionnaires and scales
}

Maria Cerrato-Lara, Montserrat Castelló Badia and Kirsti Lonka

\begin{abstract}
Studies on how students experience their $\mathrm{PhD}$ have been promoted as an indicator to improve doctoral programmes (assessment-oriented) and/or in order to understand how this collective develops in their careers (research-oriented studies). This last group has increased in the last years since researcher development has become a field of research in the context of higher education. In this respect, a database of studies measuring the $\mathrm{PhD}$ experience can be useful for researchers. Thus, we conducted a review of 53 empirical studies, focusing only on research that use questionnaires and scales in their data collection, published from 1991 to 2018 . Results along these 27 years not only shows the core elements that have been considered traditionally when measuring the $P h D$ experience, but also identifies some gaps and contributes in the clarification of this generic term. Directions for future research are offered.
\end{abstract}

\section{Introduction}

Researcher development has become a key policy issue of concern among institutional leaders in recent years, and is now a field of research in the context of higher education. In this context, the $\mathrm{PhD}$ experience, broadly defined conceptually as a journey (e.g. McAlpine, 2012; Taylor, 2011), has attracted a lot of research interest. The metaphor of a quest (McCulloch, 2013) has also been used. An alternative metaphor presented in this book is that of traversing, but how are the views of stakeholders represented? 
Studies based on the doctoral students' views have been conducted with two main aims: first, to understand doctoral students' career development (research-oriented studies); second to improve doctoral programmes (quality-assessment-oriented). The former are generally conducted on a small scale, whereas the latter are more commonly large-scale in nature, but not always.

This review focuses on large-scale studies. Therefore, we focus on those studies that use questionnaires and scales to screen the pre-doctoral population. This revision can be interesting both for administrators and for researchers in the field of doctoral education regardless of whether they are thinking of using readily available instruments for measuring the $\mathrm{PhD}$ experience or designing new ones.

Our revision can be qualified as relevant considering that we did not find any other review so far measuring doctoral experience, except the one from Evans \& Stevenson (2010) reviewing 16 studies between 1990 and 2009 measuring international doctoral students' learning experiences, but without focusing on large-scale studies.

\section{Methodology}

We used the PsycInfo and ERIC databases in our comprehensive review, with no limitation on the year of publication. The search terms included "PhD", "doctor*" and "graduate" on the one hand, and "questionnaire", "survey" and "scale" on the other, resulting in a total of nine combinations for each database. The initial electronic search resulted in 208 potential articles. Articles that evaluated the $\mathrm{PhD}$ from a perspective other than that of the student were excluded. Other common exclusion criteria were a focus on the respondents' concerns about their post- $\mathrm{PhD}$ career prospects or employment level and, to a lesser extent, their experiences in the transition to teaching. The full article was reviewed in ambiguous cases. Having selected a total of 47 original empirical studies, we 
used the "snow-ball" method in the form of a manual search of the references listed in the selected articles to find others. Google Web Search was used as well as some large-scale studies conducted by governments and universities were published as reports and not as journal articles. As a result, 53 studies were included in this review.

For presentation purposes we classified the selected studies by geographical area. For each area we classified them according to whether the data was collected among $\mathrm{PhD}$ students who were conducting their studies (understanding the experience as a current process) or when they had completed them and were doctoral graduates (in retrospect). In some cases we also found mixed-sample studies (e.g. PhD students combined with their supervisors or with recent graduates). Two main groups were also distinguished: studies examining the general $\mathrm{PhD}$ experience and those dealing with specific aspects of it.

\section{Results}

The reviewed studies are summarized according to the classification described using the questions words Where (geographical area), When (stage of the process) and What (general PhD experience or specific aspects). See Table 1:

Table 1

Studies using questionnaires \& scales measuring PhD students' experiences

\begin{tabular}{ccccl} 
Where & How & When & What & Studies \\
\hline USA and & Large & During & General & Golde \& Dore (2001) \\
Canada & -scale & PhD & Experience & Nettles \& Millett (2006) \\
& & & & Maton et al. (2016) \\
& & & Shapiro, Hudson, \& Downey (2017) \\
\cline { 3 - 4 } & & Specific & Zhao, Golde, \& McCormick (2007) \\
& Aspects & Zimak, Edwards, Johnson \& Suhr (2011) \\
& & Crede \& Borrego (2014) \\
& & & Van Dusen, Barthelemy \& Henderson (2014) \\
& & & Fang, Bednash, \& Arietti (2016) \\
& & & Miller, Duron, Bosk, Finno-Velasquez, \& Abner (2016) \\
& & & Feldon et al. (2017) \\
\cline { 3 - 4 } & After & General & Bowen \& Rudenstine (1992) \\
& PhD & Experience & Morrison, Rudd, Zumeta, \& Nerad (2011) \\
& & & NORC (2012)
\end{tabular}




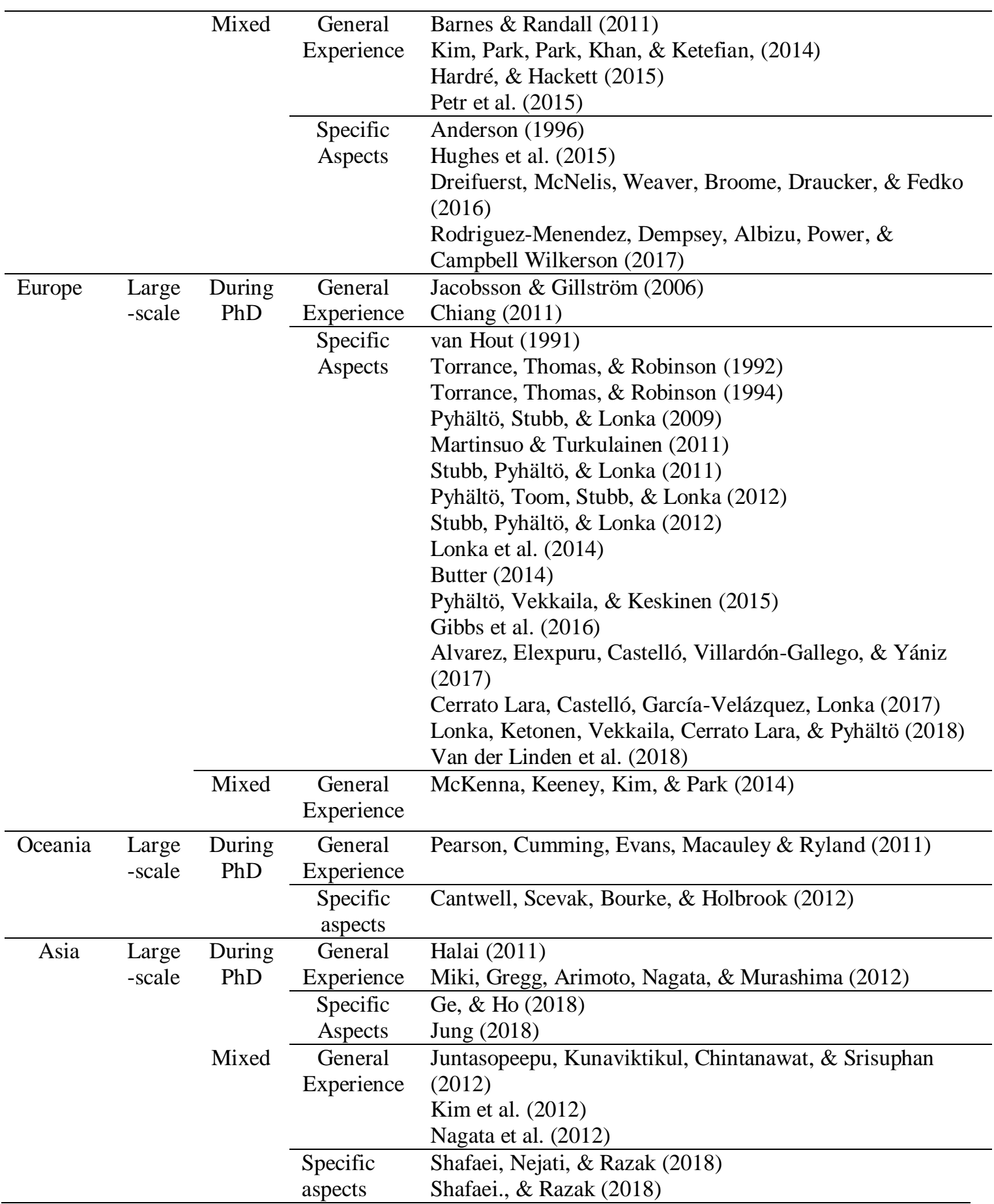

Focusing on the content of the $\mathrm{PhD}$ experience (the What), the studies in the general experience category measure the students' representations and evaluations of their $\mathrm{PhD}$ programme and institution, their interaction with supervisors and other colleagues, the working climate in which they develop their research, their personal involvement and their future expectations. Certain socio-demographic (especially gender, ethnicity and 
economic funding) and academic (especially elapsed time since the commencement of $\mathrm{PhD}$ studies) information is commonly collected. With regard to the latter, several studies investigate the factors that influence the completion of doctoral studies.

Studies on one or more specific aspects of the $\mathrm{PhD}$ experience were more numerous, and many of them were smaller in scale. Table 2 groups them by generic or specific content. A few fall into more than one content category: Shafaei, \& Razak (2018), for example, analysed the doctoral experience in terms of culture adaptions and wellbeing, and the study thus appears twice in our table - under both aspects. There were also studies in which some content was measured, as a recurrent variable rather than the main topic, as in the case of some indicators of well-being and socialization: these studies are marked with asterisks for the benefit of researchers interested in exploring them further.

Table 2

The content of studies focusing on specific aspects of the PhD experience

\begin{tabular}{|c|c|c|}
\hline Content (generic) & Content (specific) & Studies \\
\hline \multirow[t]{3}{*}{ Personal variables } & Gender & Feldon et al. (2017)*/** \\
\hline & $\begin{array}{c}\text { Culture } \\
\text { adaptation }\end{array}$ & $\begin{array}{c}\text { Jacobsson \& Gillström (2006)*; Chiang (2011); Shafaei et } \\
\text { al. (2018)*/**; Shafaei., \& Razak (2018)*/** }\end{array}$ \\
\hline & $\begin{array}{l}\text { Personality } \\
\text { aspects }\end{array}$ & Cantwell, Scevak, Bourke, \& Holbrook (2012)* \\
\hline \multicolumn{3}{|l|}{ Learning context } \\
\hline & $\begin{array}{c}\text { PhD } \\
\text { Programme }\end{array}$ & $\begin{array}{l}\text { Petr et al. (2015)*; Ge, \& Ho (2018); Rodriguez- } \\
\text { Menendez et al. (2017)*/** }\end{array}$ \\
\hline & Supervision & $\begin{array}{l}\text { Zhao et al. (2007); Pyhältö et al. (2015)**; Gibbs et al. } \\
\text { (2016); Rodriguez-Menendez et al. (2017)*/** }\end{array}$ \\
\hline & Others & Anderson (1996); Jung (2018) \\
\hline \multirow[t]{6}{*}{$\begin{array}{l}\text { Paths in the PhD } \\
\text { process }\end{array}$} & Starting a PhD & $\begin{array}{l}\text { Zimak et al. (2011); Van Dusen et al. (2014)*; Dreifuerst } \\
\text { et al. (2016) }\end{array}$ \\
\hline & $\begin{array}{l}\text { Carrying on } \\
\text { with a } \mathrm{PhD}\end{array}$ & $\begin{array}{l}\text { Martinsuo \& Turkulainen (2011); Crede \& Borrego } \\
\text { (2014)*; Van der Linden et al. (2018)*/** }\end{array}$ \\
\hline & $\begin{array}{c}\text { Needs \& } \\
\text { preferences }\end{array}$ & $\begin{array}{l}\text { Rodriguez-Menendez et al. (2017)*/**; Van der Linden et } \\
\text { al. (2018)*/** }\end{array}$ \\
\hline & Challenges & van Hout (1991); Pyhältö et al. (2012)* \\
\hline & Future steps & Van Dusen et al. (2014)*; Fang et al. (2016)* \\
\hline & Identity & Pearson et al. (2011) \\
\hline Discipline(s) & & Hughes et al. (2015) \\
\hline
\end{tabular}




\begin{tabular}{cc}
\hline Well-being & Stubb et al. (2011)*; Lonka et al. (2014)*; \\
& Shafaei et al. (2018)*/**; Shafaei., \& Razak (2018) \\
\hline Socialization & Pyhältö et al. (2009); Miller et al. (2016) \\
\hline
\end{tabular}

*One or more indicators of well-being are measured

** One or more indicators of socialization are measured

As it can be observed in Table 2, challenges and academic writing represent the older traditions. Studies analysing paths in the PhD process placed most emphasis on indicators of socialization and well-being.

Table 3 synthetizes information from Table 1 and Table 2 providing numbers and percentages:

Table 3

Descriptive analysis of the studies

\begin{tabular}{|c|c|c|c|c|}
\hline \multicolumn{3}{|c|}{ Analysed traits } & $n$ & $\%$ \\
\hline \multirow[t]{4}{*}{ Geographical area } & USA \& Canada & & 23 & $43 \%$ \\
\hline & Europe & & 19 & $36 \%$ \\
\hline & Oceania & & 2 & $4 \%$ \\
\hline & Asia & & 9 & $17 \%$ \\
\hline \multirow{3}{*}{$\begin{array}{l}\text { Stage of the } \mathrm{PhD} \\
\text { process }\end{array}$} & During PhD & & 35 & $66 \%$ \\
\hline & After $\mathrm{PhD}$ & & 3 & $6 \%$ \\
\hline & Mixed & & 15 & $28 \%$ \\
\hline \multirow{22}{*}{$\begin{array}{l}\text { Content of the } \mathrm{PhD} \\
\text { experience }\end{array}$} & General experience & & 20 & $38 \%$ \\
\hline & Specific aspects ${ }^{1}$ & & 33 & $62 \%$ \\
\hline & Personal variables & & 6 & $14 \%$ \\
\hline & & Gender & 1 & $2 \%$ \\
\hline & & Culture adaption & 4 & $10 \%$ \\
\hline & & Personality aspects & 1 & $2 \%$ \\
\hline & Learning context & & 9 & $21 \%$ \\
\hline & & $\mathrm{PhD}$ programme & 3 & $7 \%$ \\
\hline & & Supervision & 4 & $9 \%$ \\
\hline & & Others & 2 & $7 \%$ \\
\hline & Paths in the & & 13 & $30 \%$ \\
\hline & $\mathrm{PhD}$ process & Starting a PhD & 3 & $6.5 \%$ \\
\hline & & Carrying on with a $\mathrm{PhD}$ & 3 & $6.5 \%$ \\
\hline & & Needs \& preferences & 2 & $5 \%$ \\
\hline & & Challenges & 2 & $5 \%$ \\
\hline & & Future steps & 2 & $5 \%$ \\
\hline & & Identity & 1 & $2 \%$ \\
\hline & Discipline(s) & & 1 & $2 \%$ \\
\hline & Research/work & & 3 & $7 \%$ \\
\hline & Academic writing & & 5 & $12 \%$ \\
\hline & Well-being & & 4 & $9 \%$ \\
\hline & Socialization & & 2 & $5 \%$ \\
\hline \multirow{2}{*}{\multicolumn{3}{|c|}{$\begin{array}{l}{ }^{1} \text { Note. One or more indicators of well-being are } \\
\text { One or more indicators of socialization ar }\end{array}$}} & 24 & $56 \%$ \\
\hline & & & 13 & $30 \%$ \\
\hline
\end{tabular}


As can be observed, $43 \%$ of the studies were conducted in the USA and Canada, $66 \%$ focused on participants engaged in their $\mathrm{PhD}$ studies, and $62 \%$ examined specific aspects of the $\mathrm{PhD}$ experience. On the other hand, none was conducted in Africa, and 38/\% examined the $\mathrm{PhD}$ experience in general.

In relation to the theme of research, although academic writing was the most commonly studied topic in this new research field (5 studies), in terms of generic categories the paths in the $\mathrm{PhD}$ process with its longer tradition attracted the most research (30\%), followed by the learning context $(21 \%)$. On the other hand, some aspects of the $\mathrm{PhD}$ experience have been explored scarcely as it is for example the case of gender, personality aspects, identity and discipline (two per cent each).

It is also relevant to highlight that many of the studies (86\%) measured some variables of well-being and/or socialization, which seem to be meaningful indicators to explain the $\mathrm{PhD}$ experience as they can yield valuable information on student satisfaction from a more emotional perspective.

\section{Discussion}

Experience is an umbrella term encompassing several related and frequently overlapping constructs, thus it might have been difficult to identify studies that measure the $\mathrm{PhD}$ experience. This is why we did not include experience among our search terms. Our aim was not only to provide a state-of-the-art database of studies using questionnaires and scales that would be useful for researchers, but also to include the core elements that have traditionally been taken into consideration in measurements of the $P h D$ experience, thereby allowing us to describe the status of $\mathrm{PhD}$ students and further to clarify this generic term. 
Not only does our study facilitate definition of the general $\mathrm{PhD}$ experience, it also highlights specific aspects of it that have been broken down into eight themes of research. Fifty one per cent of these concern, on the one hand, to the paths in the $\mathrm{PhD}$ process relevant factors in the starting/(dis-)continuing phases, major challenges, needs \& preferences, future steps, and general aspects of student identity- and, on the other, to the learning context -mainly concerning the student's $\mathrm{PhD}$ programme and relationships with supervisors-. These two most common themes of research cover the two objectives mentioned in the introduction (enhancing understanding of career development among $\mathrm{PhD}$ students and improving doctoral programmes) quite balanced in the literature. Future research should aim not only at maintaining the balance, but also at promoting integration.

The focus in this review is on studies measuring doctoral experience from questionnaires and scales, and studies relying on data collected by other means (in interviews and discussion groups the majority) were not included. It would be interesting to carry out a state-of-the-art review of these more qualitative studies, most of which include fewer participants and emphasise in particular the socialization process and identity construction of $\mathrm{PhD}$ students. These studies with their different contents and categorizations would complement our review.

It would also be relevant in future research to focus on intervention and followup. Notably, none of the large-scale studies in our review are longitudinal. Analysing the evolution of subjects or comparing different cohorts across generations (and across cultures, especially in Asia and Africa where studies in this field are very scarce) could yield valuable information to researchers interested in analysing paths in the PhD process and/or contributing to the more general assessment of policies, practices and programmes reflecting, from certain signs of success and failure, what does and does not work in doctoral education. 
Another consideration for future research would be building up a more robust body of knowledge in some themes of research that are scarce at large-scale, like gender, personality aspects and identity, which would help to screen better the pre-doctoral population. These themes of research have, instead, been well-covered in small-scale studies (Cerrato Lara, 2014).

Finally, despite the diverse research documenting the experiences of doctoral students and although their perceptions have been used as a good assessment indicator for $\mathrm{PhD}$ programmes ${ }^{\mathrm{i}}$, in practice these efforts seem to have had little impact on educational reforms, despite claims of generalization or commonality. Indeed the impact of such studies has not been very different from that of research evaluating $\mathrm{PhD}$ education based on quantitative data on productivity, equity and efficiency obtained from university databases going back several decades (e.g. Leming, 1977). Future research should consider this crucial aspect. It should also aim to enhance understanding of doctoral graduates and non-completers in the willing to improve the structure and process of graduate education. In any case, it should be borne in mind that researcher development is an emerging field ${ }^{\mathrm{ii}}$. We are confident that future studies will soon cover the gaps we have highlighted.

\section{Acknowledgements}

This research was funded by The Finnish Funding Agency for Technology and Innovation (TEKES), project RYM Indoor Environment (462054), and the Spanish Ministry of Economy and Competitiveness (CSO2013-41108-R). The authors wish to thank Joan Nordlund, MA, for revising the language. 


\section{References}

Alvarez, M. A., Elexpuru, I., Castelló, M., Villardón-Gallego, L., \& Yániz, C. (2017).

The "why" and "what for" of research in Social Sciences: Early career researchers' conceptions. Electronic Journal of Research in Educational Psychology, 15(3), 598-623.

Anderson, M.S. (1996). Collaboration, the doctoral experience, and the departmental environment. Review of Higher Education, 19(3), 305-326.

Barnes, J.B., \& Randall, J. (2011). Doctoral student satisfaction: an examination of disciplinary, enrollment and institutional differences. Research in Higher Education, 53(1), 47-75.

Bowen, W.G., \& Rudenstine, N. (1992). In Pursuit of the PhD. Princeton University Press.

Butter, R. (2014). Ecological scales as personnel psychology's response to situational behaviour differences: Development of a conscientiousness scale for $\mathrm{PhD}$ candidates. Gedrag En Organisatie, 27(3), 290-308.

Cantwell, R. H., Scevak, J. J., Bourke, S., \& Holbrook, A. (2012). Identifying Individual Differences among Doctoral Candidates: A Framework for Understanding Problematic Candidature. International Journal of Educational Research, 53, 6879.

Cerrato Lara, M. (June 2014). Writing conceptions and psychological well-being in Ph.D. studies: students' perspectives. Retrieved from Dart-Europe E-thesis Portal, Open Access Theses and Dissertation and TDX http://hdl.handle.net/10803/145505. Legal deposit: B 15910-2014. 
Cerrato Lara, M.; Castelló, M.; García-Velázquez, R.; Lonka, K. (2017). Validation of The Writing Process Questionnaire in two Hispanic populations: Spain and Mexico. Journal of Writing Research, 9, 151-171.

Chiang, K.H. (2011). The Experience of Doctoral Studies in the UK and France: differences in epistemology, research objects and training. European Journal of Education, 46(2), 257-270.

Crede, E. \& Borrego, M. (2014). Understanding retention in US graduate programs by student nationality. Studies in Higher Education, 39(9), 1599-1616.

Dreifuerst, K. T., McNelis, A. M., Weaver, M. T., Broome, M. E., Draucker, C. B., \& Fedko, A. S. (2016). Exploring the pursuit of doctoral education by nurses seeking or intending to stay in faculty roles. Journal of Professional Nursing, 32(3), 202212. Doi:10.1016/j.profnurs.2016.01.014

Evans, C., \& Stevenson, K. (2010). The learning experiences of international doctoral students with particular reference to nursing students: A literature review. International Journal of Nursing Studies, 47(2), 239-250. doi:10.1016/j.ijnurstu.2009.05.025

Fang, D., Bednash, G. D., \& Arietti, R. (2016). Identifying barriers and facilitators to nurse faculty careers for $\mathrm{PhD}$ nursing students. Journal of Professional Nursing, 32(3), 193-201. Doi: 10.1016/j.profnurs.2015.10.001.

Feldon, D. F., Peugh, J., Maher, M. A., Roksa, J., \& Tofel-Grehl, C. (2017). Time-toCredit Gender Inequities of First-Year $\mathrm{PhD}$ Students in the Biological Sciences. CBE - Life Sciences Education, 16(1).

Ge, Y., \& Ho, K. C. (2018). The cultivation of research labor in Pacific Asia with special reference to Singapore. Asia Pacific Education Review, 19(2), 199-210. Doi:10.1007/s12564-018-9531-z 
Gibbs, S., Atkinson, C., Woods, K., Bond, C., Hill, V., Howe, J., \& Morris, S. (2016). Supervision for school psychologists in training: Developing a framework from empirical findings. School Psychology International, 37(4), 410-431. doi: $10.1177 / 0143034316653443$

Golde, C. M., \& Dore, T. M. (2001). At cross purposes: What the experiences of doctoral students reveal about doctoral education (www.phd-survey.org). Philadelphia, PA: A report prepared for The Pew Charitable Trusts.

Halai, N. (2011). Evolution of Doctoral Education in Pakistan: Challenges and Successes of Doctoral Students of Education in a Public Sector University of Pakistan. Perspectives in Education, 29, 3.

Hardré, P. L., \& Hackett, S. M. (2015). Understanding the graduate college experience: Perceptual differences by degree type, point-in-program and disciplinary subgroups. Learning Environments Research,18(3), 453-468. doi: 9443/10.1007/s10984-015-9194-1

Hughes, S., Lyddy, F., Kaplan, R., Nichols, A. L., Miller, H., Saad, C. G., ... Lynch, A.J. (2015). Highly prevalent but not always persistent: Undergraduate and graduate student's misconceptions about psychology. Teaching of Psychology, 42(1), 3442. doi: $10.1177 / 0098628314562677$.

Jacobsson, G., \& Gillström, P. (2006). International postgraduate students mirror: Catalonia, Finland, Ireland and Sweden Stockholm: Högskoleverket -Swedish National Agency for Higher Education.

Jung, J. (2018). Learning experience and perceived competencies of doctoral students in Hong Kong. Asia Pacific Education Review, 19(2), 187-198.

Juntasopeepu, P., Kunaviktikul, W., Chintanawat, R., \& Srisuphan, W. (2012). Quality of Thailand's PhD level nursing education. Thai Journal of Nursing Council, 27 (2), 36-50. 
Kim, M.J., Park, C.G., Kim, M., Lee, H., Ahn, Y-H., Kim, E.,... Lee, K-J. (2012). Quality of nursing doctoral education in Korea: Towards policy development. Journal of Advanced Nursing, 68 (7), 1494-1503.

Leming, J. S. (1977). Doctoral programs as preparation for what? The professional training perspective. Paper presented at the annual meeting of the American Educational Research Association, New York. (ERIC Document Reproduction Service No. ED 139 358).

Lonka, K., Chow, A. Keskinen, J., Hakkarainen, K. Sandström, N., \& Pyhältö, K. (2014). How to measure $\mathrm{PhD}$ students' conceptions of academic writing - and are they related to well-being? Journal of Writing Research, 5(3), 245-269.

Lonka, K., Ketonen, E., Vekkaila, J., Cerrato Lara, M., \& Pyhältö, K. (2018). Doctoral students' writing profiles and their relations to well-being and perceptions of the academic environment. Higher Education. doi: 10.1007/s10734-018-0290-x

Martinsuo, M., \& Turkulainen, V. (2011). Personal commitment, support and progress in doctoral studies. Studies in Higher Education, 36(1), 103-120.

Maton, K. I., Beason, T. S., Godsay, S., Domingo, M. R. S., Bailey, T. C., Sun, S., \& Hrabowski, F. A., III. (2016). Outcomes and Processes in the Meyerhoff Scholars Program: STEM PhD Completion, Sense of Community, Perceived Program Benefit, Science Identity, and Research Self-Efficacy. CBE - Life Sciences Education, 15(3).

McAlpine, L. (2012). Identity-Trajectories: Doctoral Journeys from Past to Present to Future. Australian Universities' Review, 54(1), 38-46.

McCulloch, A. (2013). The quest for the PhD: a better metaphor for doctoral education. International Journal for Researcher Development, 4(1), 55-66.

McKenna, H., Keeney, S., Kim, M. J., \& Park, C. G. (2014). Quality of doctoral nursing education in the United Kingdom: Exploring the views of doctoral students and 
staff based on a cross-sectional questionnaire survey. Journal of Advanced Nursing, 70(7), 1639-1652. doi: 9443/10.1111/jan.12326.

Miki, Y., Gregg, M.F., Arimoto, A., Nagata, S.,\& Murashima, S. (2012). Evaluation of doctoral nursing programs by doctoral students in Japan: Cross-sectional questionnaire survey. Japan Journal of Nursing Science, 9(2), 160-168.

Miller, J. J., Duron, J. F., Bosk, E. A., Finno-Velasquez, M., \& Abner, K. S. (2016). Peerlearning networks in social work doctoral education: An interdisciplinary model. Journal of Social Work Education, 52(3), 360-371.

Morrison, E., Rudd, E., Zumeta, W., \& Nerad, M. (2011). What Matters for Excellence in PhD Programs? Latent Constructs of Doctoral Program Quality Used by Early Career Social Scientists. Journal of Higher Education, 82(5), 535-563.

Nagata, S., Gregg, M.F., Miki, Y., Arimoto, A., Murashima, S.,\& Kim, M.J. (2012). Evaluation of doctoral nursing education in Japan by students, graduates, and faculty: A comparative study based on a cross-sectional questionnaire survey. Nurse Education Today 32, 361-367.

Nettles, M.T., \& Millett, C.M. (2006). Three magic letters: Getting to Ph.D. Baltimore, MD: The Johns Hopkins University Press.

NORC. (2012). Survey of Earned Doctorates (SED). University of Chicago. Last visit $9^{\text {th }}$ June 2015. Available at: http://www.norc.org/Research/Projects/Pages/survey-ofearned-doctorates-\%28sed\%29.aspx

Pearson, M., Cumming, J., Evans, T., Macauley, P., \& Ryland, K. (2011). How shall we know them? Capturing the diversity of difference in Australian doctoral candidates and their experiences. Studies in Higher Education, 36(5), 527-542.

Petr, C. G., Harrington, D., Kim, K., Black, B., Cunningham-Williams, R. M., \& Bentley, K. J. (2015). Quality Indicators and Expected Outcomes for Social Work PhD 
Programs: Perceptions of Social Work Students, Faculty, and Administrators. Journal of Social Work Education, 51(4), 648-667.

Pyhältö, K., Stubb, J., \& Lonka, K. (2009). Developing scholarly communities as learning environments for doctoral students. International Journal for Academic Development, 14(3), 221-232.

Pyhältö, K., Toom, A., Stubb, J., \& Lonka, K. (2012). Challenges of Becoming a Scholar: A Study of Doctoral Students' Problems and Well-Being. ISRN Education, 2012, $1-12$.

Pyhältö, K., Vekkaila, J., \& Keskinen, J. (2015). Fit matters in the supervisory relationship: Doctoral students and supervisors perceptions about the supervisory activities. Innovations in Education and Teaching International, 52(1), 4-16. doi:10.1080/14703297.2014.981836

Rodriguez-Menendez, G., Dempsey, J. P., Albizu, T., Power, S., \& Campbell Wilkerson, M. (2017). Faculty and student perceptions of clinical training experiences in professional psychology. Training and Education in Professional Psychology, 11(1), 1-9. doi:10.1037/tep0000137.supp (Supplemental)

Schmidt, M., \& Hansson, E. (2018). Doctoral students' well-being: A literature review. International Journal of Qualitative Studies on Health and WellBeing, 13(1).doi: 10.1080/17482631.2018.1508171

Shafaei, A., Nejati, M., \& Abd Razak, N. (2018). A model of psychological well-being among international students. Educational Psychology,38(1), 17-37. doi: $10.1080 / 01443410.2017 .1356447$

Shafaei, A., \& Razak, N. A. (2018). What matters most: Importance-performance matrix analysis of the factors influencing international postgraduate students' psychological and sociocultural adaptations. Quality \& Quantity: International Journal of Methodology, 52(1), 37-56. Doi:10.1007/s11135-016-0418-y 
Shapiro, V. B., Hudson, K. D., \& Downey, M. M. (2017). Institutional expectations, opportunities, and interest in the professoriate: A mixed-methods examination of satisfaction among doctoral students in social work. Journal of Social Work Education, 53(3), 520-534.

Stubb, J., Pyhältö, K., \& Lonka, K. (2011). Balancing between Inspiration and Exhaustion: PhD students' experienced socio-psychological well-being. Studies in Continuing Education, 33(1), 33-55.

Stubb, J., Pyhältö, K., \& Lonka, K. (2012). The Experienced Meaning of Working with a PhD Thesis. Scandinavian Journal of Educational Research, 56(4), 439-456.

Taylor, C. A. (2011). More than meets the eye: the use of video narratives to facilitate doctoral students' reflexivity on their doctoral journeys. Studies in Higher Education, 36(4), 441-458

Torrance, M., Thomas, G.V., \& Robinson, E.J. (1992). The writing experiences of social science research students. Studies in Higher Education, 17(2), 155-167.

Torrance, M., Thomas, G.V., \& Robinson, E.J. (1994). The writing strategies of graduate research students in the social sciences. Higher Education, 27(3), 379-92.

Van der Linden, N., Devos, C., Boudrenghien, G., Frenay, M., Azzi, A., Klein, O., \& Galand, B. (2018). Gaining insight into doctoral persistence: Development and validation of Doctorate-related Need Support and Need Satisfaction short scales. Learning and Individual Differences, 65, 100-111. doi:10.1016/j.lindif.2018.03.008

Van Dusen, B., Barthelemy, R. \& Henderson, C. (2014). Educational trajectories of graduate students in physics education research. Physical review special topics Physics Education Research 10(2), 020106-1-020106-10.

van Hout, H. (1991). A Causal Model for Assessing Problems of Dutch Research Assistants (PhD-Students). ASHE Annual Meeting Paper. 
Zhao, C-M., Golde, C.M., \& McCormick, A.C. (2007). More than a signature: How advisor choice and advisor behavior affect doctoral student satisfaction. Journal of Further and Higher Education 31 (3): 263-281.

Zimak, E.H., Edwards, K.M., Johnson, S.M., \& Suhr, J. (2011). Now or later? An empirical investigation of when and why students apply to clinical psychology $\mathrm{PhD}$ programs. Teaching of Psychology, 38 (2)118-121.

\footnotetext{
i This task should not be solely in the hands of those who provide the service such as professors, department heads, and directors or coordinators of doctoral programs, but also of those who receive it.
} 